\title{
A Narrative Review of Pneumococcal Disease in Children in the Philippines
}

\author{
Amgad Gamil • Miriam Y. Lalas • Maria Rosario Z. Capeding • \\ Anna Lisa T. Ong-Lim • Mary Ann C. Bunyi · Angelica M. Claveria
}

Received: January 4, 2021 / Accepted: March 12, 2021 / Published online: April 24, 2021

(C) The Author(s) 2021

\begin{abstract}
This narrative review describes the epidemiology of invasive pneumococcal diseases, nasopharyngeal carriage, and antibiotic resistance of Streptococcus pneumoniae serotypes, and vaccination coverage in children in the Philippines. Epidemiological data show that, despite
\end{abstract}

\footnotetext{
A. Gamil ( $₫)$

Emerging Markets Medical and Scientific Affairs, Vaccines Asia, Pfizer Inc, Pfizer Building, 5th floor, DMC, P.O. Box 502749, Dubai, UAE

e-mail: Amgad.Gamil@pfizer.com
}

M. Y. Lalas

Pfizer Inc, Makati City, Philippines

e-mail: Miriam.Lalas@pfizer.com

M. R. Z. Capeding

Medical Research Unit, Tropical Disease Foundation Inc., Makati City, Philippines

e-mail: lerosecap@yahoo.com.ph

A. L. T. Ong-Lim

Division of Infectious and Tropical Disease in Pediatrics, University of the Philippines Manila, Philippine General Hospital, Manila, Philippines e-mail: aolim1@gmail.com

M. A. C. Bunyi

Pediatric Infectious Disease Society of the Philippines, Quezon City, Philippines e-mail: macbunyi0804@gmail.com

A. M. Claveria

Pfizer Inc, Makati City, Philippines

e-mail: Gigi.M.Claveria@pfizer.com the availability of the free-of-cost 13-valent pneumococcal conjugate vaccine for infants as part of the National Immunization Program, the burden of pneumococcal disease in young children remains high in the Philippines. The significant variability in data reported between studies highlights an urgent need for active and comprehensive disease surveillance for more accurate estimates of pneumococcal disease in the country. Although data from 2001 to 2013 show high rates of pneumococcal carriage in children in the Philippines aged $<5$ years, contemporary data are lacking, again emphasizing the need for active surveillance programs. The introduction of pneumococcal conjugate vaccines has resulted in substantial declines in disease caused by pneumococcal serotypes included in the vaccines, but the emergence of pneumococcal disease due to nonvaccine serotypes is an ongoing concern. Surveillance of actively circulating serotypes is critical to better understand vaccine coverage. Antimicrobial resistance of $S$. pneumoniae remains a significant threat to public health worldwide; data regarding antibiotic resistance in young children in the Philippines are limited, but reports generally show low rates of antibiotic resistance in this group. National immunization rates have increased in recent years, yet many individuals are still unprotected from pneumococcal disease. Overall, there is a critical need for contemporary and accurate disease surveillance in the Philippines. Such data would provide better 
estimates of pneumococcal disease incidence, serotype distribution, and antibiotic resistance to better inform vaccination strategies and to ensure that children in the Philippines are best protected against pneumococcal disease.

Keywords: Antibiotic resistance; Nasopharyngeal carriage; Philippines; Pneumococcal disease; Pneumococcal vaccination

\section{Key Summary Points}

Pneumococcal disease continues to be a significant health burden among children in the Philippines.

The 13-valent pneumococcal conjugate vaccine (PCV13) is currently part of the Philippines' National Immunization Program.

The introduction of PCV13 has resulted in declines in pneumococcal disease caused by serotypes included in the vaccine, but the emergence of disease due to nonvaccine serotypes is a growing concern.

Historically, high nasopharyngeal carriage rates of up to $96 \%$ have been reported in Filipino children, but contemporary data are lacking.

Overall, comprehensive and accurate disease surveillance is needed to provide better estimates of pneumococcal disease in the country with the aim to improve vaccination coverage and better protect the population from this deadly disease.

\section{DIGITAL FEATURES}

This article is published with digital features, including a summary slide, to facilitate understanding of the article. To view digital features for this article go to https://doi.org/10.6084/ m9.figshare.14199218.

\section{INTRODUCTION}

Pneumococcal infections, which are caused by Streptococcus pneumoniae, include invasive pneumococcal diseases (IPDs; e.g., meningitis, bacteremia, bacteremic pneumonia) and noninvasive diseases such as nonbacteremic pneumonia, sinusitis, and otitis media [1-3]. Globally, pneumonia is the leading cause of death from infectious disease in children; in $2017,808,694$ children aged $<5$ years died of pneumonia, accounting for $15 \%$ of all deaths of children in this age group $[4,5]$. In the Western Pacific region, which for World Health Organization (WHO) reporting purposes includes the Philippines, the incidence of pneumococcal pneumonia in 2015 was 831 per 100,000 children aged $<5$ years, causing an estimated 11,600 deaths [6].

Colonization of the nasopharynx by $S$. pneumoniae precedes pneumococcal disease, and subsequent bacterial carriage is a prerequisite for disease transmission $[7,8]$. In developing countries, infants and young children are the main carriers of S. pneumoniae [1]. Data pertaining to nasopharyngeal carriage remain crucial to understanding the true burden of disease in any given country and could help inform vaccination strategies.

Although more than 90 serotypes of $S$. pneumoniae have been identified, only a small proportion cause disease [1]. Vaccines are available to prevent pneumococcal infections, including the 10- and 13-valent pneumococcal conjugate vaccines (PCVs), which are recommended for healthy children aged $<2$ years. Additionally, the 23-valent pneumococcal polysaccharide vaccine (PPSV23) is recommended in children aged $\geq 2$ years with comorbidities but only after primary vaccination with a PCV [1]. Highervalency PCVs are also under development for pediatric and adult indications [9-12]. Specifically in the Philippines, 13-valent PCV (PCV13) has been approved for use in children and adults since 2014 and functions to induce vaccine serotype-specific antibodies, which 
protect against pneumococcal diseases caused by serotypes included in the vaccine; PCV13 is currently included free of cost for infants as a $3+0$ schedule, as part of the Philippines' National Immunization Program (NIP) $[8,13,14]$.

Vaccination with PCVs has resulted in substantial reductions in IPD-related deaths in children aged $<5$ years worldwide, decreasing from 735,000 deaths in 2000 to 294,000 deaths in 2015 [6]. Despite this reduction, there still remains a significant global burden of pneumococcal disease in children [15]. As serotype prevalence changes over time and by geographic region, and new vaccines covering emerging disease-causing serotypes are being developed [1], robust contemporary surveillance programs are required for countries to continually monitor serotype prevalence and adjust vaccination policies to ensure optimal protection from disease.

The overall situation of Filipino children is an important context to consider when describing pneumococcal disease in this population. A 2018 analysis conducted by UNICEF and the Government of the Philippines reported that, despite rapid economic growth, $31 \%$ of children were living below the basic needs poverty line [16]. Health concerns among Filipino children included declines in childhood immunization coverage and increases in vaccine-preventable diseases, such as rubella and measles [16]. Such economic and health factors may impact vaccine access/uptake and pneumococcal disease incidence among children.

The purpose of this review is to describe the epidemiology of IPD, nasopharyngeal carriage, and antibiotic resistance of $S$.pneumoniae serotypes, and vaccination coverage in children in the Philippines. The available articles summarized in this review highlight the gap in contemporary data and support the need for active pneumococcal disease surveillance in the Philippines to inform ongoing vaccination strategies. This review also discusses vaccination policies in other Asian countries, which may further inform pneumococcal vaccination strategies in the Philippines.

\section{METHODS}

A literature search for this narrative review was performed using PubMed. Search terms of (Pneumococci OR Pneumococcus OR S. pneumoniae OR Streptococcus pneumoniae) AND (Children OR Pediatrics OR Infants OR Toddlers) were used in conjunction with (Epidemiology OR Burden OR Prevalence OR Incidence OR Mortality OR Morbidity OR Death OR Fatality OR Fatalities OR Cases OR CFR OR Surveillance OR Notification) OR (Nasopharyngeal OR Carriage OR Colonization OR NPC OR Acquisition) OR (Prevalence OR Cases OR Serotypes OR Serotyping OR Surveillance) OR (Antibiotic resistance OR Antimicrobial resistance OR Resistance OR Antibiotics OR Antimicrobials OR AMR) OR (Vaccination OR Vaccines OR PCV OR PCV7 OR PCV10 OR PCV13 OR PPSV23 OR PCV15 OR PCV20 OR Pneumococcal Conjugate Vaccine OR PPV23 OR Coverage OR Uptake) to search for publications pertaining to the Philippines or Asia (vaccine-related publications only for Asia). The search was limited to English-language articles published between January 1, 2000, and February 3, 2021. Altogether, 107 articles were retrieved, of which 11 were relevant to the topics included in this review. As necessary, references cited within the retrieved publications were used; the opinion of authors and/or experts in the field were also obtained as needed. Additionally, references from the authors' personal files and published reports from the Department of Health of the Philippines and other regulatory agencies when relevant were reviewed. This article is based on previously conducted studies and does not contain any studies with human participants or animals performed by any of the authors.

\section{EPIDEMIOLOGY AND BURDEN OF PNEUMOCOCCAL DISEASE}

Information regarding the incidence and mortality rates of pneumococcal disease in the Philippines is limited, with much of the available estimates relying on prospective studies. Between 2007 and 2009, a hospital-based study 
Table 1 Prevalence of $S$. pneumoniae among clinical isolates in the Philippines

\begin{tabular}{|c|c|c|c|c|c|}
\hline $\begin{array}{l}\text { Period of } \\
\text { study }\end{array}$ & Age group & Specimen & Diagnosis & $\begin{array}{l}\text { Specimens } \\
\text { positive for } \\
\text { S. pneumoniae (\%) }\end{array}$ & Reference \\
\hline \multirow[t]{3}{*}{$1984-1986$} & \multirow[t]{3}{*}{$<5$ years } & \multirow[t]{3}{*}{ Urine } & ALRI & 3.7 & \multirow[t]{3}{*}{ Tupasi et al. [18] } \\
\hline & & & $\begin{array}{l}\text { Bacterial pneumococcal } \\
\text { infection }\end{array}$ & 0 & \\
\hline & & & Nonbacteremic ALRI & 4.6 & \\
\hline \multirow[t]{2}{*}{$1990-1992$} & \multirow[t]{2}{*}{$<5$ years } & \multirow[t]{2}{*}{ Blood } & ALRI & 3.7 & \multirow[t]{2}{*}{ Capeding et al. [25] } \\
\hline & & & Bacteremia & $35^{\mathrm{a}}$ & \\
\hline 1994-1996 & $<5$ years & Blood & $\begin{array}{l}\text { Pneumonia or suspected } \\
\text { sepsis or meningitis }\end{array}$ & $1.3^{\mathrm{a}}$ & Lupisan et al. [24] \\
\hline $1994-2000$ & $<5$ years & $\begin{array}{l}\text { Blood and } \\
\text { cerebrospinal } \\
\text { fluid }\end{array}$ & $\begin{array}{l}\text { Severe or very severe } \\
\text { pneumonia, suspected } \\
\text { sepsis or meningitis }\end{array}$ & 1.3 & Sombrero et al. [19] \\
\hline 2008-2009 & 8 days -13 years & Blood & Severe pneumonia & $13^{\mathrm{a}}$ & Suzuki et al. [20] \\
\hline \multirow[t]{3}{*}{2018} & \multirow[t]{3}{*}{ All ages } & Respiratory & NA & 0.32 & \multirow{3}{*}{$\begin{array}{l}\text { Republic of the } \\
\text { Philippines } \\
\text { Department of } \\
\text { Health [22] }\end{array}$} \\
\hline & & Blood & NA & 0.18 & \\
\hline & & $\begin{array}{l}\text { Cerebrospinal } \\
\text { fluid }\end{array}$ & NA & 0 & \\
\hline \multirow[t]{3}{*}{2019} & \multirow[t]{3}{*}{ All ages } & Respiratory & NA & 0.39 & \multirow{3}{*}{$\begin{array}{l}\text { Republic of the } \\
\text { Philippines } \\
\text { Department of } \\
\text { Health [23] }\end{array}$} \\
\hline & & Blood & NA & 0.16 & \\
\hline & & $\begin{array}{l}\text { Cerebrospinal } \\
\text { fluid }\end{array}$ & NA & 0 & \\
\hline
\end{tabular}

$A L R I$ acute lower respiratory tract infection, $N A$ not available

a Of blood culture samples positive for a bacterial pathogen

reported the incidence of IPD in children aged $<5$ years to be 25.38 to 33.49 per 100,000 individuals, with a case fatality rate of $33.3 \%$ [17]. The study identified that very young children aged 28 days to $<6$ months were the most vulnerable, with a reported incidence of IPD ranging from 41.89 to 178.23 per 100,000 individuals. A longitudinal modeling study of pneumococcal disease mortality in children aged 1 to 59 months estimated that in 2015, there were 3182 pneumonia deaths, 357 meningitis deaths, and 318 nonmeningitis deaths due to infection with S. pneumoniae in the Philippines [6].

Several studies have reported the prevalence of S.pneumoniae among clinical isolates from children in the Philippines (Table 1). Specifically, a study from 1984 to 1986 in 537 children aged $<5$ years who were hospitalized for acute lower respiratory tract infection (ALRI) found that $3.7 \%$ of urine samples collected were positive for $S$. pneumoniae antigen [18]. Additionally, the study reported that $S$. pneumoniae was not detected in the urine of any patient (0/9) with bacterial pneumococcal infection but that the 
pathogen was detected in $4.6 \%(23 / 496)$ of children with nonbacteremic ALRI [18]. A longitudinal prospective study from 1994 to 2000 reported that pneumococci could be identified in $1.3 \%$ of invasive isolates from children aged $<5$ years [19]. A 2008 to 2009 prospective study conducted in children (median age 9 months) hospitalized in a regional medical center for severe pneumonia found that out of 31 blood culture samples positive for a bacterial pathogen, 13\% (4/31) were positive for S. pneumoniae [20]. In 2010, a systematic review concluded that among 2,428,488 children aged 0 to 4 years with pneumonia in the Philippines, 170,059 of these cases $(7 \%)$ were attributable to S. pneumoniae [21]. The data from passive surveillance by the Philippine Department of Health Antimicrobial Resistance Surveillance Program (ARSP) show that out of $489 \mathrm{~S}$. pneumoniae-positive clinical isolates collected in 2018, 108 (22\%) were from children aged 0 to 5 years [22]. The data show that most infections $(83 \%)$ were presumed to be community acquired. The majority of $S$. pneumoniae infections were reported from respiratory specimens (59\%), with $32 \%$ from blood and $2 \%$ from cerebrospinal fluid [22]. The remaining isolates were from wound, urine, tissue, and other body fluids [22]. The most recent ARSP report found that of the 581 S. pneumoniae isolates in 2019, $67 \%, 28 \%$, and $1 \%$ of $S$. pneumoniae were collected from respiratory secretions, blood, and CSF, respectively [23]; overall, $11.4 \%(66 / 581)$ of S. pneumoniae isolates were collected from children aged 0 to 4 years [23].

In a study of 956 Filipino children $<5$ years of age who were admitted to hospital between April 1994 and March 1996 because of pneumonia or suspected sepsis or meningitis, S. pneumoniae was the most common pathogen among blood cultures; overall, $8.9 \%$ of cultures were positive for a pathogen, of which $1.3 \%$ of blood cultures were positive for $S$. pneumoniae [24]. Another study of Filipino children aged $<5$ years conducted in the early 1990 s reported S. pneumoniae in blood cultures of 3.7\% ALRIs and in $35.0 \%$ of patients with confirmed bacteremia [25]. Data on the frequency distribution of bacterial meningitis from three tertiary hospitals within the metropolitan region of Manila from 2002 to 2006 showed that S. pneumoniae and Haemophilus influenzae type B were the most prevalent etiological agents, with mortality rates of $23.5 \%$ and $5.0 \%$, respectively [26].

Overall, these data show that the burden of pneumococcal disease in young children remains high in the Philippines. However, considering the significant variability in data reported between studies, there remains an urgent need for active and comprehensive disease surveillance for more accurate estimates of pneumococcal disease in the country. Even though PCV13 is currently included in the NIP of the Philippines, accurate estimates could better inform ongoing and future vaccination strategies [13].

\section{NASOPHARYNGEAL CARRIAGE}

In many countries, high rates of pneumococcal carriage have been observed in children aged $<5$ years [27]. Table 2 summarizes studies that report nasopharyngeal carriage rates among children in the Philippines. A 1994 to 2000 longitudinal study of children aged $<5$ years from a rural region of the country reported an overall 45\% (1367/3028) nasopharyngeal carriage rate [19]. A short-term study conducted between 1998 and 1999 in children aged $<5$ years who were attending daycare centers or outpatient clinics reported a carriage rate of $33 \%(N=307)$ [28]. In a randomized clinical trial conducted in 2000 to 2004 to evaluate the efficacy of an 11-valent PCV, pre-enrollment assessments revealed that among 1111 infants, 53\% had nasopharyngeal carriage by 6 weeks of age [29]. A 2005 study among 500 children aged 2 months to 5 years who were attending well visits at a hospital in Manila reported that $38 \%$ of children had nasopharyngeal carriage; among these children, a $34 \%$ carriage rate was reported in those aged $<6$ months [30]. Other studies have shown that carriage acquisition of $S$. pneumoniae can occur very early in life; a prospective study from 2000 in Filipino infants $(N=173)$ reported an approximate $50 \%$ carriage rate by age 12 weeks, which increased to $90 \%$ by age 
Table 2 Nasopharyngeal pneumococcal carriage rates in children in the Philippines

\begin{tabular}{lllll}
\hline Period of study & $\boldsymbol{N}$ & Age group & $\begin{array}{l}\text { Nasopharyngeal } \\
\text { Carriage, } \%\end{array}$ & Reference \\
\hline $1994-2000$ & 3028 & $<5$ years & 45 & Sombrero et al. [19] \\
$1998-1999$ & 307 & $<5$ years & 33 & Lee et al. [28] \\
2000 & 173 & $\leq 12$ weeks & 50 & Holmlund et al. [31] \\
& & $\leq 45$ weeks & 90 & \\
$2000-2004$ & 1111 & $\leq 6$ weeks & 53 & Väkeväinen et al. [29] \\
2005 & 500 & 2 months-5 years & 38 & Capeding et al. [30] \\
& & $<6$ months & 34 & Wright et al. [32] \\
$2012-2013$ & 154 & At birth & 33 & \\
\hline
\end{tabular}

45 weeks [31]. Similarly, another study from 2012 to 2013 in 154 healthy Filipino infants randomized to receive 10-valent PCV (PCV10) reported that nasopharyngeal colonization rates increased with age; carriage rates rose from 33\% at birth up to $96 \%$ at 12 months of age, regardless of vaccination status [32].

Contemporary estimates of nasopharyngeal carriage in young Filipino children are not available. The paucity of such data emphasizes the need for active surveillance programs to determine current pneumococcal carriage rates in the country. Such data could in turn provide better estimates of the effectiveness of the ongoing PCV immunization program in the country.

\section{SEROTYPE DISTRIBUTION AND ESTIMATED VACCINATION COVERAGE}

The introduction of PCVs and their inclusion into national immunization programs worldwide have resulted in substantial declines in disease caused by the pneumococcal serotypes included in the vaccines $[1,33]$. However, the emergence of pneumococcal disease due to nonvaccine serotypes remains an ongoing concern [34]. As such, surveillance of actively circulating serotypes remains critical to better understand vaccine coverage and to further inform ongoing vaccination strategies.

The serotype distribution of S.pneumoniae from studies conducted in children in the Philippines is summarized in Table 3. Overall, surveillance studies on serotype prevalence in the Philippines over the past 2 decades show that serotypes $1,5,6 \mathrm{~A}, 6 \mathrm{~B}, 9 \mathrm{~V} / \mathrm{A}, 12 \mathrm{~A}, 14,18$, $19 \mathrm{~A}, 19 \mathrm{~F}$, and $23 \mathrm{~F}$ are among the most prevalent serotypes in children [17, 35-37], while serotypes $1,3,5,6 \mathrm{~A}, 6 \mathrm{~B}, 7$, and $19 \mathrm{~A}$ are among the most prevalent serotypes among adults aged $>50$ years $[35,38]$.

A large international surveillance study by the Asian Network for Surveillance of Resistant Pathogens (ANSORP) conducted in 2000 to 2001 reported that the most prevalent serotype among sterile site isolates collected from Filipino children in Manila was 6B (18\%); other prevalent serotypes included 19F (14\%), 9 (9\%), and 19A (5\%) [37]. Subsequently, a 2007 to 2009 prospective surveillance study in hospitalized Filipino children aged 3 to 5 years in 3 urban areas of the country showed that the serotypes with the highest prevalence were 5 $(22 \%)$ and 1 (17\%) in Quezon City; 18F (50\%), 6B (25\%), and 12A (25\%) in Manila; and 14 (31\%) and 6B (23\%) in Muntinlupa City. Other prevalent serotypes in all 3 areas included 2,5 , $6 \mathrm{~A}, 6 \mathrm{~B}, 10 \mathrm{C}, 11 \mathrm{~B}, 11 \mathrm{~F}, 12 \mathrm{~F}, 14,15 \mathrm{C}, 18 \mathrm{C}, 18 \mathrm{~F}$, $19 \mathrm{~F}$, and 23F [17]. The estimated vaccine coverage of PCV10 and PCV13 was 56\% and 61\%, 
Table 3 Serogroup and serotype distribution and pneumococcal vaccine coverage in the Philippines

\begin{tabular}{|c|c|c|c|c|c|c|c|c|}
\hline \multirow{2}{*}{$\begin{array}{l}\text { Period of } \\
\text { study }\end{array}$} & \multirow{2}{*}{$\begin{array}{l}\text { Age } \\
\text { group } \\
\text { (years) }\end{array}$} & \multirow[t]{2}{*}{ Region } & \multirow{2}{*}{$\begin{array}{l}\text { Specimen } \\
\text { type }\end{array}$} & \multicolumn{3}{|c|}{ Serotype (\%) } & \multirow{2}{*}{$\begin{array}{l}\text { PCV10/ } \\
\text { PCV13 } \\
\text { coverage } \\
(\%)\end{array}$} & \multirow[t]{2}{*}{ Reference } \\
\hline & & & & $\begin{array}{l}\text { PCV10/ } \\
\text { PCV13 } \\
\text { serotypes }\end{array}$ & $\begin{array}{l}\text { PCV13/ } \\
\text { non- } \\
\text { PCV10 } \\
\text { serotypes }\end{array}$ & $\begin{array}{l}\text { Nonvaccine } \\
\text { serotypes }\end{array}$ & & \\
\hline \multirow[t]{3}{*}{ 2000-2001 } & $<18^{\mathrm{a}}$ & Manila & Sterile & $6 \mathrm{~B}(18)$ & $19 \mathrm{~A}(5)$ & NA & NA & Song et al. [37] \\
\hline & & & & $19 F(14)$ & & & & \\
\hline & & & & $9(9)$ & & & & \\
\hline \multirow[t]{6}{*}{ 2007-2009 } & $3-5$ & Quezon City & Sterile & $5(22)$ & $11 \mathrm{~B}(6)$ & $2(11)$ & $56 / 61$ & Capeding et al. \\
\hline & & & & $1(17)$ & & $11 \mathrm{~F}(6)$ & & {$[17]$} \\
\hline & & & & $6 \mathrm{~B}(6)$ & & $12 \mathrm{~F}(6)$ & & \\
\hline & & & & $14(6)$ & & $15 \mathrm{C}(6)$ & & \\
\hline & & & & $18 \mathrm{C}(6)$ & & $18 \mathrm{~F}(6)$ & & \\
\hline & & & & $6 \mathrm{~A}(6)$ & & & & \\
\hline \multirow[t]{2}{*}{ 2007-2009 } & $3-5$ & Manila & Sterile & 6B (25) & & $18 \mathrm{~F}(50)$ & $25 / 25$ & Capeding et al. \\
\hline & & & & & & $12 \mathrm{~A}(25)$ & & [17] \\
\hline \multirow[t]{5}{*}{ 2007-2009 } & $3-5$ & Muntinlupa & Sterile & $14(31)$ & & $2(8)$ & $85 / 85$ & Capeding et al. \\
\hline & & City & & 6B (23) & & $10 \mathrm{C}(8)$ & & [17] \\
\hline & & & & $5(8)$ & & $23 \mathrm{~F}(8)$ & & \\
\hline & & & & $18 \mathrm{C}(8)$ & & & & \\
\hline & & & & $19 \mathrm{~F}(8)$ & & & & \\
\hline \multirow[t]{2}{*}{ 2004-2011 } & $<5$ & Countrywide & Sterile & $1(13)$ & & NA & $70 / 74$ & Sia et al. [36] \\
\hline & & & & $6^{\mathrm{b}}(18)$ & & & & \\
\hline \multirow[t]{12}{*}{ 2012-2013 } & $\leq 1$ & Muntinlupa & Nonsterile & 6B (10) & $6 \mathrm{~A}(8)$ & $23 \mathrm{~A}(8)$ & NA & Wright et al. [32] \\
\hline & & City & & $14(3)$ & & 19C (5) & & \\
\hline & & & & $19 \mathrm{~F}(8)$ & & $16(3)$ & & \\
\hline & & & & $45(8)$ & & $18 \mathrm{C}(3)$ & & \\
\hline & & & & & & 19A (3) & & \\
\hline & & & & & & $19 \mathrm{C}(3)$ & & \\
\hline & & & & & & $20(3)$ & & \\
\hline & & & & & & $5 B(3)$ & & \\
\hline & & & & & & $10 \mathrm{~A}(3)$ & & \\
\hline & & & & & & $11 \mathrm{~F}(3)$ & & \\
\hline & & & & & & $15 B / C(3)$ & & \\
\hline & & & & & & $15 \mathrm{~F}(3)$ & & \\
\hline
\end{tabular}


Table 3 continued

\begin{tabular}{|c|c|c|c|c|c|c|c|c|}
\hline \multirow{2}{*}{$\begin{array}{l}\text { Period of } \\
\text { study }\end{array}$} & \multirow{2}{*}{$\begin{array}{l}\text { Age } \\
\text { group } \\
\text { (years) }\end{array}$} & \multirow[t]{2}{*}{ Region } & \multirow{2}{*}{$\begin{array}{l}\text { Specimen } \\
\text { type }\end{array}$} & \multicolumn{3}{|c|}{ Serotype (\%) } & \multirow{2}{*}{$\begin{array}{l}\text { PCV10/ } \\
\text { PCV13 } \\
\text { coverage } \\
(\%)\end{array}$} & \multirow[t]{2}{*}{ Reference } \\
\hline & & & & $\begin{array}{l}\text { PCV10/ } \\
\text { PCV13 } \\
\text { serotypes }\end{array}$ & $\begin{array}{l}\text { PCV13/ } \\
\text { non- } \\
\text { PCV10 } \\
\text { serotypes }\end{array}$ & $\begin{array}{l}\text { Nonvaccine } \\
\text { serotypes }\end{array}$ & & \\
\hline \multirow[t]{8}{*}{ 2012-2014 } & \multirow[t]{8}{*}{$<5$} & \multirow[t]{8}{*}{ Countrywide } & \multirow[t]{8}{*}{ Sterile } & $5(13)$ & $3(2)$ & \multirow[t]{8}{*}{ NA } & \multirow[t]{8}{*}{ NA } & \multirow{8}{*}{$\begin{array}{l}\text { Philippine Health } \\
\text { Assessment } \\
\text { Technology } \\
\text { Unit [35] }\end{array}$} \\
\hline & & & & $1(11)$ & \multirow[t]{7}{*}{$6 \mathrm{~A}(13)$} & & & \\
\hline & & & & $14(11)$ & & & & \\
\hline & & & & $23 \mathrm{~F}(7)$ & & & & \\
\hline & & & & $18 \mathrm{C}(4)$ & & & & \\
\hline & & & & $4(2)$ & & & & \\
\hline & & & & $6 \mathrm{~B}(2)$ & & & & \\
\hline & & & & $9 \mathrm{~V} / \mathrm{A}(2)$ & & & & \\
\hline \multirow[t]{8}{*}{ 2012-2019 } & \multirow[t]{8}{*}{$<5$} & \multirow[t]{8}{*}{ Countrywide } & \multirow[t]{8}{*}{ Sterile } & $14(9)$ & $3(4)$ & \multirow[t]{8}{*}{ NA } & \multirow[t]{8}{*}{$48 / 59$} & \multirow{8}{*}{$\begin{array}{l}\text { Philippine Health } \\
\text { Assessment } \\
\text { Technology } \\
\text { Unit [35] }\end{array}$} \\
\hline & & & & $18 \mathrm{C}(9)$ & 19A (4) & & & \\
\hline & & & & $1(6)$ & $6 \mathrm{~A}(3)$ & & & \\
\hline & & & & $23 \mathrm{~F}(6)$ & & & & \\
\hline & & & & $6 \mathrm{~B}(6)$ & & & & \\
\hline & & & & $5(5)$ & & & & \\
\hline & & & & $9 \mathrm{~V} / \mathrm{A}(4)$ & & & & \\
\hline & & & & $4(3)$ & & & & \\
\hline \multirow[t]{10}{*}{ 2015-2019 } & \multirow[t]{10}{*}{$<5$} & \multirow[t]{10}{*}{ Countrywide } & \multirow[t]{10}{*}{ Sterile } & $14(8)$ & $19 \mathrm{~A}(6)$ & \multirow[t]{10}{*}{ NA } & \multirow[t]{10}{*}{ NA } & \multirow{10}{*}{$\begin{array}{l}\text { Philippine Health } \\
\text { Assessment } \\
\text { Technology } \\
\text { Unit [35] }\end{array}$} \\
\hline & & & & $18 \mathrm{C}(7)$ & $3(4)$ & & & \\
\hline & & & & $1(6)$ & $6 \mathrm{~A}(2)$ & & & \\
\hline & & & & $23 \mathrm{~F}(6)$ & & & & \\
\hline & & & & $9 \mathrm{~V} / \mathrm{A}(4)$ & & & & \\
\hline & & & & $6 \mathrm{~B}(3)$ & & & & \\
\hline & & & & $4(2)$ & & & & \\
\hline & & & & $5(2)$ & & & & \\
\hline & & & & $7(2)$ & & & & \\
\hline & & & & $19 \mathrm{~F}(1)$ & & & & \\
\hline
\end{tabular}

NA not available, $P C V 10$ 10-valent pneumococcal conjugate vaccine, $P C V 13$ 13-valent pneumococcal conjugate vaccine

${ }^{a}$ Exact ages for children examined not provided; ages specified based on standard cutoffs for children

b Only serotype numbers reported 
respectively, in Quezon City; 25\% for both PCV10 and PCV13 in Manila; and 85\% for both PCV10 and PCV13 in Muntinlupa City [17].

Another source of data on serotype distribution is the ARSP (Table 3). A study summarizing these publicly available data from 2004 to 2011 reported that during this 8-year period, the most common serotypes in children aged $\leq 5$ years were $1(13 \%)$ and $6(18 \%)$; the estimated vaccine coverage for PCV10 and PCV13 was $70 \%$ and $74 \%$, respectively [36]. A report from the Philippine Government Health Technology Assessment (HTA) unit summarizing ARSP data from 2012 to 2019 showed that the most common serotypes in children aged $<5$ years old were 14 and $18 \mathrm{C}$ (each $9 \%$ ); other prevalent serotypes included $1,23 \mathrm{~F}$, and $6 \mathrm{~B}$ (each $6 \%$ ), serotype $5(5 \%), 3,19 \mathrm{~A}$, and $9 \mathrm{~V} / \mathrm{A}$ (each 4\%), and 6A and 4 (each 3\%) [35]. The estimated vaccine coverage for PCV10 and PCV13 was $48 \%$ and 59\%, respectively [35]. The Research Institute for Tropical Medicine (RITM) also conducts passive pneumococcal surveillance; summary data reported by the HTA unit from 2015 to 2019 show that the current prevalent serotypes among children aged $<5$ years include $14(8 \%), 18 \mathrm{C}(7 \%), 19 \mathrm{~A}$ (6\%), 1 (6\%), 23F (6\%), 3 (4\%), 9V/A (4\%), and $6 \mathrm{~B}(3 \%)$, followed by 4,5 , and $6 \mathrm{~A}$, and 7 (each 2\%) [35].

Although serotype distribution among pneumococcal isolates from Filipino children (invasive and lower respiratory tract) has been described, data regarding nasopharyngeal carriage isolates are scarce, and contemporary estimates are not available. The latest available data are from a study conducted in Muntinlupa City from 2012 to 2013, which reported that the dominant serotype found in nasopharyngeal isolates from 39 healthy Filipino children aged $\leq 1$ year was $6 \mathrm{~B}(10 \%)$; other prevalent serotypes included 6A, 19F, 23A, and 45 (all $8 \%), 19 \mathrm{C}(5 \%)$, and 5B, 10A, 11F, 14, 15B/C, 15F, 16, 18C, 19A, 19C, and 20 (all 3\%) [32].

\section{ANTIMICROBIAL RESISTANCE}

Antimicrobial resistance of S.pneumoniae remains a significant threat to public health worldwide [1]. In Asia specifically, many countries have consistently reported high rates of antibiotic resistance [39], suggesting that the number of resistant strains continues to be on the rise [40]. Additionally, high rates of antibiotic use have been reported in the Philippines; frequent antibiotic use preceding a medical visit can not only confound culture-based diagnostics but also contribute to the increasing rates of antibiotic resistance of $S$. pneumoniae [17, 19]. For these reasons, it remains imperative to continually perform routine surveillance regarding antibiotic resistance so that optimal disease prevention and treatment strategies can be implemented.

An international surveillance study conducted from 2000 to 2001 of pneumococcal isolates among all age groups in the Philippines $(N=22)$ showed that all isolates were susceptible to penicillin, amoxicillin/clavulanate, cefuroxime, ceftriaxone, levofloxacin, moxifloxacin, and gatifloxacin; resistance was only reported for erythromycin (18\%) and ciprofloxacin (9\%) [37] (Table 4). A more recent study reported that the penicillin susceptibility rate of S. pneumoniae among all age groups in the Philippines was 92\% in 2015 to 2016 [41]. Another recent survey from 2016 to 2018 reported very low antimicrobial resistance among isolates $(N=17)$ collected from patients with community-acquired respiratory tract infections; all tested pneumococcal isolates were susceptible to amoxicillin, amoxicillin/clavulanic acid, clarithromycin, erythromycin, and fluoroquinolones for three susceptibility limits used [42]. Resistance to cephalosporins was only reported for cefaclor, with $6 \%$ to $35 \%$ of isolates considered resistant depending on the susceptibility limits used [42]. Additionally, susceptibility to penicillin, azithromycin, and trimethoprim/sulfamethoxazole ranged from $94 \%$ to $100 \%, 94 \%$ to $100 \%$, and $88 \%$ to $100 \%$, respectively, depending on the susceptibility limits used [42].

Passive surveillance data from the ARSP show that antimicrobial resistance rates may be on the rise for all ages in the Philippines $[22,23,43]$. In 2013 , it was reported that only $0 \%$ and $5 \%$ of all respiratory and invasive isolates $(N=274)$ were resistant to penicillin 
Table 4 Resistance of pneumococcal isolates to antimicrobials in the Philippines

\begin{tabular}{|c|c|c|c|c|c|c|}
\hline $\begin{array}{l}\text { Period of } \\
\text { study }\end{array}$ & $\begin{array}{l}\text { Age } \\
\text { group } \\
\text { (years) }\end{array}$ & Region & $\begin{array}{l}\text { Isolates, } \\
N\end{array}$ & Sample type & Isolates resistant (\%) & References \\
\hline \multirow[t]{5}{*}{$1994-2000$} & \multirow[t]{5}{*}{$<5$} & \multirow[t]{5}{*}{ Rural Philippines } & 1048 & $\begin{array}{l}\text { Pneumococcal } \\
\text { isolates }\end{array}$ & $\begin{array}{l}\text { Oxacillin (4) } \\
\text { Penicillin (2) }\end{array}$ & \multirow[t]{5}{*}{ Sombrero et al. [19] } \\
\hline & & & \multirow[t]{3}{*}{1013} & \multirow[t]{3}{*}{$\begin{array}{l}\text { Nasopharyngeal } \\
\text { isolates }\end{array}$} & $\begin{array}{l}\text { Tetracycline }(4) \\
\text { Chloramphenicol }(0.4)\end{array}$ & \\
\hline & & & & & $\begin{array}{l}\text { Trimethoprim/ } \\
\text { sulfamethoxazole }(0.4)\end{array}$ & \\
\hline & & & & & Erythromycin (0.3) & \\
\hline & & & 35 & Invasive isolates & Tetracycline (5.7) & \\
\hline 1998-1999 & $<5$ & Manila & 95 & $\begin{array}{l}\text { Nasopharyngeal } \\
\text { isolates }\end{array}$ & $\begin{array}{l}\text { Trimethoprim/ } \\
\text { sulfamethoxazole (2) } \\
\text { Tetracycline (1) }\end{array}$ & Lee et al. [28] \\
\hline $2000-2001$ & All ages & Countrywide & 22 & $\begin{array}{l}\text { Pneumococcal } \\
\text { isolates }\end{array}$ & $\begin{array}{l}\text { Erythromycin (18) } \\
\text { Ciprofloxacin (9) }\end{array}$ & Song et al. [37] \\
\hline 2007-2009 & $<5$ & Manila & 47 & $\begin{array}{l}\text { Pneumococcal } \\
\text { isolates }\end{array}$ & Erythromycin (2) & Capeding et al. [17] \\
\hline 2013 & All ages & Countrywide & 274 & $\begin{array}{l}\text { Pneumococcal } \\
\text { isolates }\end{array}$ & $\begin{array}{l}\text { Trimethoprim/ } \\
\text { sulfamethoxazole (20) } \\
\text { Erythromycin (6) } \\
\text { Penicillin (0-5) } \\
\text { Levofloxacin (2) } \\
\text { Chloramphenicol (3) }\end{array}$ & $\begin{array}{l}\text { Republic of } \\
\text { Philippines } \\
\text { Department of } \\
\text { Health [43] }\end{array}$ \\
\hline 2018 & All ages & Countrywide & 489 & $\begin{array}{l}\text { Pneumococcal } \\
\text { isolates }\end{array}$ & $\begin{array}{l}\text { Trimethoprim/ } \\
\text { sulfamethoxazole (17) } \\
\text { Penicillin (1-16) } \\
\text { Erythromycin (13) } \\
\text { Chloramphenicol (5) } \\
\text { Ceftriaxone (3) } \\
\text { Levofloxacin (1) }\end{array}$ & $\begin{array}{l}\text { Republic of } \\
\text { Philippines } \\
\text { Department of } \\
\text { Health [22] }\end{array}$ \\
\hline $2015-2016$ & All ages & Countrywide & $<20$ & $\begin{array}{l}\text { Pneumococcal } \\
\text { isolates }\end{array}$ & $\begin{array}{l}\text { Penicillin (92) } \\
\text { (susceptibility) }^{\mathrm{a}}\end{array}$ & Sader et al. [41] \\
\hline
\end{tabular}


Table 4 continued

\begin{tabular}{lllllll}
\hline $\begin{array}{l}\text { Period of } \\
\text { study }\end{array}$ & $\begin{array}{l}\text { Age } \\
\text { group } \\
\text { (years) }\end{array}$ & Region & $\begin{array}{l}\text { Isolates, } \\
\boldsymbol{N}\end{array}$ & Sample type & Isolates resistant (\%) & References \\
\hline $2016-2018$ & All ages & $\begin{array}{c}\text { Quezon City } \\
\text { and Bonifacio } \\
\text { Global City }\end{array}$ & 17 & $\begin{array}{c}\text { Pneumococcal } \\
\text { isolates }\end{array}$ & Cefaclor (35) & $\begin{array}{r}\text { Torumkuney et al. } \\
{[42]}\end{array}$ \\
2019 & All ages & Countrywide & 404 & $\begin{array}{c}\text { Pneumococcal } \\
\text { isolates }\end{array}$ & $\begin{array}{l}\text { Co-trimoxazole (14) } \\
\text { Penicillin (1-13) }\end{array}$ & $\begin{array}{c}\text { Republic of } \\
\text { Philippines } \\
\text { Department of } \\
\end{array}$ \\
& & & & Erythromycin (9) & Health [23] \\
& & & & Ceftriaxone (2) & \\
& & & & Chloramphenicol (2) & \\
\hline
\end{tabular}

${ }^{a}$ Only susceptibility available

according to nonmeningitis and meningitis susceptibility limits, respectively [43]. By 2018, $1 \%$ and $16 \%$ of all isolates $(N=489)$ were resistant to penicillin using the nonmeningitis and meningitis susceptibility limits, respectively [22]. Similarly, in 2019 , penicillin resistance of all isolates $(n=404)$ was $1 \%$ using nonmeningitis susceptibility limits and 13\% using meningitis susceptibility limits [23]. In 2013, resistance was also reported for trimethoprim/sulfamethoxazole (20\%), erythromycin (6\%), chloramphenicol (3\%), and levofloxacin (2\%) [43]. In comparison, in 2018, resistance to trimethoprim/sulfamethoxazole and levofloxacin decreased slightly to $17 \%$ and $1 \%$, respectively, while resistance to erythromycin and chloramphenicol increased to $13 \%$ and $5 \%$, respectively [22]. In 2013, no isolates were reported to be resistant to ceftriaxone; however, by $2018,3 \%$ of isolates were resistant to ceftriaxone [22,43]. In 2019 , overall resistance rates of $S$. pneumoniae isolates against co-trimoxazole, erythromycin, levofloxacin, ceftriaxone, and chloramphenicol were $14 \%$, $9 \%, 2 \%, 2 \%$, and $2 \%$, respectively; changes in resistance rates from 2018 to 2019 were not statistically significant for all antimicrobials assessed [23].

Data regarding antibiotic resistance in young children in the Philippines are more limited. However, low antibiotic resistance rates have generally been reported in children [17, 19, 28]. A 1998 to 1999 study conducted in healthy children aged $<5$ years from Manila reported that $1.0 \%$ and $2.0 \%$ of nasopharyngeal carriage isolates were resistant to tetracycline and trimethoprim/sulfamethoxazole, respectively [28]. The same study did not observe resistance among carriage isolates to several antimicrobials including penicillin, cefotaxime, cefuroxime, amoxicillin/clavulanate, imipenem, erythromycin, or chloramphenicol. Similarly, a longer-term study from 1994 to 2000 in rural areas of the Philippines also reported low prevalence of acquired antimicrobial resistance among invasive and nasopharyngeal carriage isolates [19]. Among pneumococcal isolates $(N=1048), 4.0 \%$ were resistant to oxacillin and $2.1 \%$ were intermediately resistant to penicillin [19]. Among nasopharyngeal isolates ( $N=1013), 3.6 \%$ were resistant to tetracycline, $0.4 \%$ to chloramphenicol, $0.3 \%$ to 
erythromycin, and $0.4 \%$ to trimethoprim/sulfamethoxazole [19]. A 2007 to 2009 prospective surveillance study in children aged $\leq 5$ years hospitalized with pneumonia or IPD reported very low antibiotic resistance rates; only $2 \%$ of isolates $(1 / 47)$ were resistant to erythromycin and no isolates were found to be resistant to penicillin, trimethoprim/sulfamethoxazole, amoxicillin, ampicillin, ceftriaxone, levofloxacin, or vancomycin [17].

\section{PNEUMOCOCCAL VACCINATION IN THE PHILIPPINES}

Worldwide, the introduction of PCVs has led to significant decreases in the incidence of IPD $[1,4,33]$. Specifically, in very young children, the inclusion of PCVs into NIPs has led to significant decreases in IPD caused by vaccine serotypes [1]. The WHO deems PCVs to be efficacious, well tolerated, and cost-effective, and recommends that they should be included in NIPs worldwide $[1,8]$.

In many countries, access to immunizations against life-threatening infectious diseases, including pneumococcal disease, has been improved through support from the Global Alliance for Vaccines and Immunizations (GAVI) [44]. However, because the Philippines is a lower-middle-income country and the national income surpasses eligibility limits set by GAVI, it does not qualify for financial support from GAVI $[45,46]$. Consequently, there are considerable economic barriers to universal PCV implementation in the Philippines [47]. Despite these financial constraints, the Philippine government made a positive step toward a national PCV program by implementing a regional PCV10 program in 2013, covering two regions with high disease burden [48], targeting $25 \%$ to $30 \%$ of children in the country [47]. Subsequently, an economic assessment of PCVs demonstrated that although both PCV10 and PCV13 were cost-effective compared with no vaccination, PCV13 was more cost-effective compared with PCV10 [47]. On the basis of these results, the Philippine government made the decision to implement PCV13 as part of the NIP in 2014; PCV13 is currently available free of cost to all children aged $<1$ year as a $3+0$ vaccination schedule in 14 out of 17 regions of the Philippines [13, 14, 35, 48].

Since the introduction of PCVs in the Philippines, several cost-effectiveness and health outcomes studies have reinforced the decision by the Philippine government to include PCVs in the NIP $[47,49]$. A study conducted in 2014 concluded that a $2+1$ PCV10 vaccination schedule in the Philippines was more cost-effective compared with no vaccination [50]. The same study further revealed that although PCV10 would lead to greater reductions in acute otitis media compared with PCV13, both vaccines would result in comparable reductions in IPD and community-acquired pneumonia (CAP) cases and associated deaths [50]. Overall, on the basis of a conservative estimate, the study concluded that PCV10 would produce greater cost savings and thus was a better vaccination strategy compared with PCV13 for the Philippines at the time [50]. However, a subsequent 2014 study examining the lifetime costs and outcomes for a $2+1$ PCV10 or PCV13 vaccination schedule compared with no vaccination concluded that PCV13 was more cost-effective compared with PCV10 for inclusion in the Philippine NIP [47]. An October 2020 report published by the HTA unit of the Philippines suggests that, on the basis of cost-effectiveness modeling, PCV13 may result in larger savings compared with PCV10 as a result of greater serotype coverage. Overall, the modeling study predicted that, compared with PCV10, PCV13 could potentially avert an additional 13,235 acute otitis media cases; 24,775 pneumonia cases and 625 pneumonia-related deaths; and 7954 IPD cases and 3651 IPD-related deaths [35].

In addition to the costs of the vaccines themselves, another consideration to implementing large-scale healthcare programs is the availability of specialized healthcare professionals to deliver immunization services [49]. A 2016 study examining the impact of vaccination programs on healthcare-related human resources in the Philippines concluded that although implementing PCV13 would require greater staffing of full-time general practitioners, nurses, and midwives, it would 
simultaneously lower the need for other healthcare professionals including pediatricians, infectious disease specialists, and pharmacists, among others [49]. The study also found no differences in healthcare resource requirements between implementing a PCV10 or PCV13 program [49]. The WHO recommends that PCV vaccine choice in any country should be based on a number of factors including price and supply, as well as local and regional prevalence of serotypes and antimicrobial resistance patterns [8]. These data, together with the presence of circulating PCV13-specific serotypes in the population (Table 3), suggest that PCV13 may be a better pneumococcal vaccine option for the Philippines [49].

Although the implementation of a PCV program is a crucial step toward combating pneumococcal disease, the success of universal immunization programs depends on widespread vaccination coverage. According to the WHO/UNICEF national immunization coverage reports, only $45 \%$ of the world's infant population (74.1 million) were estimated to be receiving a PCV in 2018 [51]. In the Philippines, the vaccination coverage rate for a three-dose PCV was 35\% for all ages in 2014; however, by 2018 , vaccine coverage rates had increased to $60 \%$ for the same three-dose schedule [52]. Despite these pronounced increases in national PCV immunization rates, many individuals are still unprotected from pneumococcal disease [52]. To expand immunization coverage in countries such as the Philippines, it remains important to ensure that individuals living in more rural regions of the country have equal access to vaccinations as those living in urban areas [53]. One study using spatial epidemiological methods to examine variations in vaccine efficacy of an 11-valent PCV in children aged $<2$ years in Bohol, Philippines, reported that the greatest vaccine efficacy was observed in areas with poor access to healthcare [53]. The lack of access to care likely prevents timely treatment of pneumococcal disease, increasing the burden of disease in rural areas [53]. This suggests that vaccination policymakers may need to specially target rural regions of the Philippines to ensure they are protected from pneumococcal disease.
Ensuring greater vaccination coverage could have a significant impact on reducing the incidence of vaccine-serotype disease in the country. An analysis of serotype prevalence in the PCV13 pre-introduction era (2012 to 2014) reported a high prevalence of certain PCV10/ PCV13 serotypes in children aged $<5$ years, including 5 (13\%), 6A (13\%), 14 (11\%), 1 (11\%), and $23 \mathrm{~F}(7 \%)$ [35]. However, a subsequent analysis in the PCV13 post-introduction period (2015 to 2019) surveillance data showed great decreases in some of the aforementioned serotypes among children aged $<5$ years [35]. Notably, there were small increases in certain PCV10/PCV13 serotypes between the PCV13 pre-introduction and post-introduction eras, including serotypes 3, 18C, 6B, and 9V/A [35]. Additionally, nonvaccine serotypes comprised $45 \%$ of all serotypes identified during the postintroduction time compared with $33 \%$ of all serotypes in the pre-introduction period [35]; the emergence of nonvaccine serotypes following the introduction of a PCV has also been reported in other countries [34]. It remains important to note that because of the passive nature of data collection, lack of national representativeness due to the limited coverage of sentinel sites, nonuniversal vaccination implementation, and suboptimal vaccination uptake, the true impact of PCV implementation based on existing PCV13 pre-introduction and postintroduction data cannot be ascertained at this time $[35,52]$. This suggests the need for a more comprehensive active surveillance system to provide a better understanding of the true effectiveness of PCVs in the Philippines. Such studies can further inform ongoing pneumococcal vaccination policies in the country.

Vaccine hesitancy, listed among the WHO's 10 threats to global health in 2019, has the ability to undermine vaccine coverage rates $[54,55]$. In 2017, there was much publicity and panic after it emerged that the dengue vaccine, which had been given to 800,000 school children in the Philippines, potentially increased the risk of severe dengue in children who had never been infected with dengue before vaccination $[56,57]$. This may have led to a decrease in vaccine confidence and an increase in vaccine hesitancy, despite the fact that the dengue 
vaccine is deemed an essential medicine by the WHO [58]. A study of 2500 participants (1000 surveyed in 2015 and 1500 surveyed in 2018) reported a dramatic drop in overall vaccine confidence, with 93\% strongly agreeing that vaccines are important in 2015 compared with $32 \%$ in 2018 . The perception of vaccine safety was also affected, with the percentage of participants strongly agreeing that vaccines are safe decreasing from $82 \%$ in 2015 to $21 \%$ in 2018 [57]. A 2019 survey of 110 parents or caregivers with at least one child aged $<2$ years reported that, although more than $95 \%$ of respondents believed that vaccines are protective, more than one-third were hesitant about or refused vaccines [56]. The extent of vaccine hesitancy regarding PCV coverage in the Philippines remains to be examined.

\section{DISCUSSION}

Vaccination against pneumococcal disease is an important and cost-effective public health measure that is especially crucial in low- and middle-income countries. The introduction of PCVs was a key step in reducing the global burden of pneumococcal disease. However, because of the emergence of nonvaccine serotypes, improved surveillance initiatives and higher-valent PCVs are needed within the Philippines and other neighboring Asian countries. This review on pneumococcal disease epidemiology and carriage in children $<5$ years of age in the Philippines and other Asian countries revealed (1) high rates of pneumococcal carriage, (2) increased incidence of disease caused by nonvaccine serotypes, and (3) low rates of antimicrobial resistance.

Examination of pneumococcal vaccination policies in other Asian countries may further inform ongoing pneumococcal vaccination strategies in the Philippines. In several countries in Asia, the introduction of PCV into the NIP has resulted in reduction in the incidence of IPD [59-64]. Specifically, in Mongolia, a study showed that before introduction of the vaccine, PCV13 serotypes accounted for up to $45 \%$ and $70 \%$ of all pneumococci tested in infants and children, respectively [59]. Comparatively, in
2016, 1 year after the introduction of PCV13, vaccine serotype carriage in unvaccinated infants (aged 5 to 8 weeks) and children (aged 12 to 23 months) decreased by $51 \%$ and $52 \%$, respectively [59]. In Cambodia, a 2013 to 2014 hospital-based study in Siem Reap showed that PCV13 serotypes accounted for $88 \%$ of IPD isolates and $63 \%$ of outpatient nasopharyngeal carriage isolates [60]. PCV13 was introduced in Cambodia in 2015, and by the following year, PCV13 serotype colonization decreased significantly from $58 \%$ to $42 \%(P=0.0001)$ in children aged $<1$ year living in Siem Reap [62]. Notably, PCV13 coverage was $66 \%$ for children aged $<1$ year in this study [62]. More recently, a longitudinal study in Cambodia examining nasopharyngeal colonization rates from 2014 to 2018 reported the PCV13 vaccine efficacy to be $39 \%$ in children aged $<5$ years [65]. In Taiwan, a 2007 to 2013 study in children aged $\leq 5$ years reported the vaccine efficacy of PCV7/PCV10 and PCV13 against IPD to be $45 \%$ and $74 \%$, respectively [61]. Taiwan introduced PCV13 in 2011, and subsequently a 2012 to 2015 study reported that the incidence of IPD for children aged $\leq 5$ years decreased by $69 \%$ during this time [63]. A more recent study from Taiwan reported that the incidence of IPD decreased by up to $77 \%$ in patients aged $<18$ years between 2012 and 2015 [64]. The introduction of PCV13 in Taiwan also led to decreases in the incidence of IPD caused by serotype 19A in children aged $<5$ years; IPD incidence decreased by $33 \%$ to $44 \%$ yearly from 2012 to 2017 [63].

In Pakistan, a matched case-control study conducted at 16 hospitals in Sindh Province, in children aged $<5$ years from July 2013 to March 2017, showed the estimated efficacy of PCV10 against vaccine-type IPD was $72.7 \%$ $(95 \%$ CI $-7.2 \%, 92.6 \%)$ with at least one dose [66]. The vaccine efficacy point estimates for PCV10 were high and increased with increasing number of doses. However, vaccine efficacy estimates did not reach statistical significance, possibly because of low power. A systematic review of IPD among children aged $<12$ years from 1970 to 2014 in Bangladesh, Nepal, India, Pakistan, and Sri Lanka found that the strains covered in PCV10 contributed to an average of 
$50 \%$ of IPD (ranging from $37 \%$ in Pakistan to $62 \%$ in India) [67].

The introduction of PCV into NIPs has also led to reductions in CAP. In Japan, following the introduction of PCV13 in 2013, one study reported that the annualized incidence of hospitalized CAP in children aged $<5$ years decreased from 14.3 per 1000 children in 2012 to 9.7 per 1000 children in 2018 [68]. Specifically, the incidence of CAP due to vaccine serotypes $1,3,7 \mathrm{~F}$, and 19A decreased in the years following the introduction of PCV13 in Japan; an overall decrease in the prevalence of all PCV13 serotypes from $30 \%$ to $13 \%$ was observed during this period [68]. Overall, reductions in IPD incidence and CAP in other Asian countries demonstrate successful implementation of vaccination programs against $S$. pneumoniae and may serve as a model for the Philippines.

Antimicrobial resistance of S.pneumoniae continues to be of concern in Southeast Asia $[69,70]$. However, national PCV programs have played a role in reducing antibiotic resistance rates in several Asian countries $[38,61,64$, $68,71]$. In Japan, PCV13 was introduced in 2013; a study assessing pneumococcal disease from 2012 to 2014 in individuals aged 2 months to 16 years observed decreases in the percentage of IPD isolates that were nonsusceptible to penicillin and cefotaxime during this time [71]. In Taiwan, PCV13 was introduced in 2011; a study of pneumococcal isolates collected from hospitalized children and adolescents from 2012 to 2016 noted that between 2012 and 2014, significant decreases in antibiotic resistance rates were observed for serotype 19F (91\% to $62 \%$ ) and $19 \mathrm{~A}$ (91\% to 56\%) [64]. Another study from Taiwan observed that among pediatric and adult pneumococcal isolates, penicillin resistance rates decreased following PCV13 introduction from $28 \%$ in 2012 to $8 \%$ in 2014 [61]. During the 3-year study period, serotypes $19 \mathrm{~A}$ and $19 \mathrm{~F}$ were reported to have the highest penicillin resistance rates, which decreased from $52 \%$ and $42 \%$ to $14 \%$ and $18 \%$, respectively [61]. In a systematic review of IPD among children aged $<12$ years from 1970 to 2014 in Bangladesh, Nepal, India, Pakistan, and Sri Lanka, the authors reported that Sri Lanka was the only country with high penicillin resistance rates (almost 90\%); the other countries had penicillin resistance rates of less than 10\% [67].

Despite the success of PCV programs to address antibiotic resistance, rising rates of antibiotic resistance to pneumococci in several Asian countries continue to be reported [38]. Notably, a longitudinal study in Taiwan reported increases in penicillin resistance rates for PCV13 serotypes 19F and 19A in 2016, after reporting declining penicillin resistance rates between 2012 and 2014 [64]. Similarly, a recent study in Japan in children aged $<5$ years hospitalized for CAP reported an increase in penicillin $\mathrm{G}$ resistance for nonvaccine serotypes $15 \mathrm{~A}$ and 35B between 2016 and 2018 [68]. Several factors could be responsible for these increases in antibiotic resistance, including rampant use of antimicrobials in healthcare settings in addition to the spread of antimicrobial-resistant bacterial strains [38]. Overall, such reports highlight the need to continually perform routine surveillance to monitor antibiotic resistance among pneumococcal strains even in the presence of an ongoing PCV immunization program [38].

This narrative review should be assessed in light of several inherent limitations. First, data pertaining to epidemiology of pneumococcal disease and serotype distribution among pneumococcal isolates in the Philippines were limited to prospective studies and passive surveillance, thus providing incomplete insight into the true burden of pneumococcal disease in the country. Second, contemporary data on nasopharyngeal carriage in young Filipino children are not available; because children are the main carriers of $S$. pneumoniae, such data are needed to better understand the prevalence of the pathogen in the country. Finally, antimicrobial resistance data in young Filipino children are limited, suggesting the need for greater data collection among different age groups. The lack of comprehensive epidemiological carriage and antimicrobial data emphasize the unmet need for active disease surveillance in the Philippines. 


\section{CONCLUSIONS}

The Philippines has taken a positive step toward combatting pneumococcal disease through the introduction of PCV13 into the NIP [13]; however, there remains a critical need for contemporary and accurate disease surveillance. Such data would provide better estimates of pneumococcal disease incidence, serotype distribution, and antibiotic resistance to better inform ongoing vaccination policies and to ensure that the Philippine population is best protected against pneumococcal disease.

\section{ACKNOWLEDGEMENTS}

Funding. This work and the article processing charges, including the journal's Rapid Service Fee, were sponsored by Pfizer Inc.

Medical Writing and Editorial Assistance. Editorial/medical writing support was provided by Srividya Ramachandran, PhD, of ICON plc (North Wales, PA, USA) and was funded by Pfizer Inc.

Authorship. All named authors meet the International Committee of Medical Journal Editors (ICMJE) criteria for authorship for this article, take responsibility for the integrity of the work as a whole, and have given their approval for this version to be published.

Authors' Contributions. All authors contributed to the conception and design of the article, interpreting the relevant data, drafting of the manuscript, and/or critically revising the manuscript for intellectual contribution.

Disclosures. Amgad Gamil, Miriam Y. Lalas, and Angelica M. Claveria are employees of Pfizer Inc, and may hold stock/stock options. Maria Rosario Z. Capeding, Mary Ann C. Bunyi, and Anna Lisa T. Ong-Lim have no conflict of interests to report.

Compliance with Ethics Guidelines. This article is based on previously conducted studies and does not contain any studies with human participants or animals performed by any of the authors.

Data Availability. Data sharing is not applicable to this article as all data included are publicly available in the cited sources.

Open Access. This article is licensed under a Creative Commons Attribution-NonCommercial 4.0 International License, which permits any non-commercial use, sharing, adaptation, distribution and reproduction in any medium or format, as long as you give appropriate credit to the original author(s) and the source, provide a link to the Creative Commons licence, and indicate if changes were made. The images or other third party material in this article are included in the article's Creative Commons licence, unless indicated otherwise in a credit line to the material. If material is not included in the article's Creative Commons licence and your intended use is not permitted by statutory regulation or exceeds the permitted use, you will need to obtain permission directly from the copyright holder. To view a copy of this licence, visit http://creativecommons.org/licenses/by$\mathrm{nc} / 4.0 /$.

\section{REFERENCES}

1. World Health Organization. Pneumococcal vaccines WHO position paper-2012. Wkly Epidemiol Rec. 2012;87:129-44.

2. Blasi F, Mantero M, Santus P, Tarsia P. Understanding the burden of pneumococcal disease in adults. Clin Microbiol Infect. 2012;18:7-14.

3. Drijkoningen JJ, Rohde GG. Pneumococcal infection in adults: burden of disease. Clin Microbiol Infect. 2014;20:45-51.

4. World Health Organization. Pneumonia: key facts. 2019. https://www.who.int/news-room/fact-sheets/ detail/pneumonia. Accessed 23 Mar 2021.

5. Dadonaite B, Roser M. 2020. Pneumonia. https:// ourworldindata.org/pneumonia. Accessed 23 Mar 2021. 
6. Wahl B, O'Brien KL, Greenbaum A, et al. Burden of Streptococcus pneumoniae and Haemophilus influenzae type $B$ disease in children in the era of conjugate vaccines: global, regional, and national estimates for 2000-15. Lancet Glob Health. 2018;6:e744-57.

7. Bogaert D, De Groot R, Hermans PW. Streptococcus pneumoniae colonisation: the key to pneumococcal disease. Lancet Infect Dis. 2004;4:144-54.

8. World Health Organization. 2020. Pneumococcal conjugate vaccines in infants and children under 5 years of age: WHO position paper-February 2019. https://apps.who.int/iris/bitstream/handle/10665/ 310968/WER9408.pdf?ua=1. Accessed 23 Mar 2021.

9. Thompson A, Lamberth E, Severs J, et al. Phase 1 trial of a 20-valent pneumococcal conjugate vaccine in healthy adults. Vaccine. 2019;37:6201-7.

10. Stacey HL, Rosen J, Peterson JT, et al. Safety and immunogenicity of 15-valent pneumococcal conjugate vaccine (PCV-15) compared to PCV-13 in healthy older adults. Hum Vaccin Immunother. 2019;15:530-9.

11. Greenberg D, Hoover PA, Vesikari T, et al. Safety and immunogenicity of 15 -valent pneumococcal conjugate vaccine (PCV15) in healthy infants. Vaccine. 2018;36:6883-91.

12. US National Institutes of Health. 2020. Trial to evaluate the safety and immunogenicity of a multivalent pneumococcal vaccine in healthy infants. NCT03512288. https://clinicaltrials.gov/ct2/show/ NCT03512288. Accessed 23 Mar 2021.

13. Republic of the Philippines Department of Health. 2020. Department of Health continues to use PCV13 contrary to reports. https://www.doh.gov. $\mathrm{ph} /$ doh-press-release/doh-continues-to-use-PCV13contrary-to-reports. Accessed 23 Mar 2021.

14. World Health Organization. 2020. WHO vaccinepreventable diseases monitoring system 2020 global summary: Philippines. https://apps.who.int/ immunization_monitoring/globalsummary/ countries?countrycriteria $\% 5$ Bcountry $\% 5 \mathrm{D} \% 5 \mathrm{~B} \%$ 5D=PHL\#. Accessed 23 Mar 2021.

15. Balsells E, Guillot L, Nair H, Kyaw MH. Serotype distribution of Streptococcus pneumoniae causing invasive disease in children in the post-PCV era: a systematic review and meta-analysis. PLoS One. 2017;12:e0177113.

16. National Economic and Development Authority (NEDA) and UNICEF Philippines. Situation analysis of children in the Philippines: a summary report. 2018. https://www.unicef.org/philippines/media/ 556/file/Situation\%20Analysis\%20of\% 20Children $\% 20$ in $\% 20$ the $\% 20$ Philippines $\% 20-\%$
20Executive\%20Summary.pdf. Accessed 26 Jan 2021.

17. Capeding MR, Bravo L, Santos J, et al. Prospective surveillance study of invasive pneumococcal disease among urban children in the Philippines. Pediatr Infect Dis J. 2013;32:e383-9.

18. Tupasi TE, Lucero MG, Magdangal DM, et al. Etiology of acute lower respiratory tract infection in children from Alabang. Metro Manila Rev Infect Dis. 1990;12(Suppl 8):S929-39.

19. Sombrero L, Nissinen A, Esparar G, et al. Low incidence of antibiotic resistance among invasive and nasopharyngeal isolates of Streptococcus pneumoniae from children in rural Philippines between 1994 and 2000. Eur J Clin Microbiol Infect Dis. 2008;27: 929-35.

20. Suzuki A, Lupisan S, Furuse Y, et al. Respiratory viruses from hospitalized children with severe pneumonia in the Philippines. BMC Infect Dis. 2012;12:267.

21. Rudan I, O'Brien KL, Nair H, et al. Epidemiology and etiology of childhood pneumonia in 2010: estimates of incidence, severe morbidity, mortality, underlying risk factors and causative pathogens for 192 countries. J Glob Health. 2013;3:010401.

22. Republic of Philippines Department of Health. Antimicrobial resistance surveillance program annual report. https://arsp.com.ph/publications/. Accessed 22 Oct 2020.

23. Antimicrobial Resistance Surveillance Program Annual Report-2019. Manila: antimicrobial resistance surveillance program; 2020.

24. Lupisan SP, Herva E, Sombrero LT, et al. Invasive bacterial infections of children in a rural province in the central Philippines. Am J Trop Med Hyg. 2000;62:341-6.

25. Capeding MR, Sombrero LT, Paladin FJ, et al. Etiology of acute lower respiratory infection in Filipino children under five years. Southeast Asian J Trop Med Public Health. 1994;25:684-7.

26. Bravo LC, Asian Strategic Alliance for Pneumococcal Disease Prevention Working Group. Overview of the disease burden of invasive pneumococcal disease in Asia. Vaccine. 2009;27:7282-91.

27. Adegbola RA, DeAntonio R, Hill PC, et al. Carriage of Streptococcus pneumoniae and other respiratory bacterial pathogens in low and lower-middle income countries: a systematic review and metaanalysis. PLoS One. 2014;9:e103293. 
28. Lee NY, Song JH, Kim S, et al. Carriage of antibioticresistant pneumococci among Asian children: a multinational surveillance by the Asian Network for Surveillance of Resistant Pathogens (ANSORP). Clin Infect Dis. 2001;32:1463-9.

29. Väkeväinen $M$, Soininen A, Lucero $M$, et al. Serotype-specific hyporesponsiveness to pneumococcal conjugate vaccine in infants carrying pneumococcus at the time of vaccination. J Pediatr. 2010;157(778-83):e1.

30. Capeding MRZ, Tan RR, Calimon NC, et al. Streptococcus pneumoniae carriage rate in Filipino children attending well baby clinics. Philipp J Pediatr. 2009;58:15-9.

31. Holmlund E, Quiambao B, Ollgren J, Nohynek H, Käyhty H. Development of natural antibodies to pneumococcal surface protein A, pneumococcal surface adhesin $\mathrm{A}$ and pneumolysin in Filipino pregnant women and their infants in relation to pneumococcal carriage. Vaccine. 2006;24:57-65.

32. Wright MS, McCorrison J, Gomez AM, et al. Strain level Streptococcus colonization patterns during the first year of life. Front Microbiol. 2017;8:1661.

33. Whitney CG, Farley MM, Hadler J, et al. Decline in invasive pneumococcal disease after the introduction of protein-polysaccharide conjugate vaccine. N Engl J Med. 2003;348:1737-46.

34. Liao WH, Lin SH, Lai CC, et al. Impact of pneumococcal vaccines on invasive pneumococcal disease in Taiwan. Eur J Clin Microbiol Infect Dis. 2010;29:489-92.

35. Republic of the Philippines Department of Health. Reassessment of 10- versus 13-valent pneumococcal conjugate vaccines (PCV) in the Philippines. 2020. https://hta.doh.gov.ph/2020/10/26/reassessmentof-10-versus-13-valent-pneumococcal-conjugatevaccines-pcv-in-the-philippines/. Accessed 23 Mar 2021.

36. Sia S, Carlos C, Hufano MC, et al. Serotype distribution and antimicrobial resistance of Streptococcus pneumoniae in the Philippines, 2004-2011. Philipp J Pathol. 2017;2:23.

37. Song JH, Jung SI, Ko KS, et al. High prevalence of antimicrobial resistance among clinical Streptococcus pneumoniae isolates in Asia (an ANSORP study). Antimicrob Agents Chemother. 2004;48:2101-7.

38. Kim SH, Chung DR, Song JH, et al. Changes in serotype distribution and antimicrobial resistance of Streptococcus pneumoniae isolates from adult patients in Asia: emergence of drug-resistant nonvaccine serotypes. Vaccine. 2020;38:6065-73.
39. Hung IF, Tantawichien T, Tsai YH, Patil S, Zotomayor R. Regional epidemiology of invasive pneumococcal disease in Asian adults: epidemiology, disease burden, serotype distribution, and antimicrobial resistance patterns and prevention. Int $\mathrm{J}$ Infect Dis. 2013;17:e364-73.

40. Kim SH, Song JH, Chung DR, et al. Changing trends in antimicrobial resistance and serotypes of Streptococcus pneumoniae isolates in Asian countries: an Asian Network for Surveillance of Resistant Pathogens (ANSORP) study. Antimicrob Agents Chemother. 2012;56:1418-26.

41. Sader HS, Mendes RE, Le J, et al. Antimicrobial susceptibility of Streptococcus pneumoniae from North America, Europe, Latin America, and the Asia-Pacific Region: results from 20 years of the SENTRY Antimicrobial Surveillance Program (1997-2016). Open Forum Infect Dis. 2019;6: S14-23.

42. Torumkuney D, Van PH, Thinh LQ, et al. Results from the Survey of Antibiotic Resistance (SOAR) 2016-18 in Vietnam, Cambodia, Singapore and the Philippines: data based on CLSI, EUCAST (dosespecific) and pharmacokinetic/pharmacodynamic (PK/PD) breakpoints. J Antimicrob Chemother. 2020;75:i19-42.

43. Antimicrobial Resistance Surveillance Reference Laboratory. Antimicrobial resistance surveillance program 2013 annual report. Manila, Philippines: 2014.

44. GAVI TVA. 2020. Healthy children with a healthy future. https://www.gavi.org/sites/default/files/ document/2019/GAVI_Alliance_replenishment_ brochure.pdf. Accessed 23 Mar 2021.

45. GAVI TVA. 2020. Eligibility. https://www.gavi.org/ types-support/sustainability/eligibility. Accessed 23 Mar 2021.

46. The World Bank. 2020. The World Bank in the Philippines. https://www.worldbank.org/en/ country/philippines. Accessed 23 Mar 2021.

47. Haasis MA, Ceria JA, Kulpeng W, Teerawattananon $\mathrm{Y}$, Alejandria M. Do pneumococcal conjugate vaccines represent good value for money in a lowermiddle income country? A cost-utility analysis in the Philippines. PLoS One. 2015;10:e0131156.

48. Kumar R, Arora N, Santosham M. South Asia symposium on pneumococcal disease and the promise of vaccines - meeting report. Vaccine. 2016;34: 2622-6.

49. Chootipongchaivat S, Chantarastapornchit V, Kulpeng $\mathrm{W}$, et al. Vaccination program in a resource- 
limited setting: a case study in the Philippines. Vaccine. 2016;34:4814-9.

50. Zhang XH, Nievera MC, Carlos J, et al. Cost-effectiveness analysis of pneumococcal vaccination with the pneumococcal polysaccharide NTHi protein D conjugate vaccine in the Philippines. Value Health Reg Issues. 2014;3:156-66.

51. Johns Hopkins Bloomberg School of Public Health International Vaccine Access Center (IVAC). VIEWhub report: global vaccine introduction and implementation. September 2019. https://viewhub.org/sites/default/files/2020-05/VIEW-hub_ Report_Sep2019.pdf. Accessed 20 Aug 2020.

52. World Health Organization. 2020. Pneumococcal conjugate 3rd dose coverage. https://apps.who.int/ immunization_monitoring/globalsummary/ timeseries/tscoveragepcv3.html. Accessed 22 June 2020 .

53. Root ED, Lucero M, Nohynek H, et al. Distance to health services modifies the effect of an 11-valent pneumococcal vaccine on pneumonia risk among children less than 2 years of age in Bohol, Philippines. Int J Epidemiol. 2017;46:706-16.

54. World Health Organization. 2020. Ten threats to global health in 2019. https://www.who.int/newsroom/spotlight/ten-threats-to-global-health-in2019. Accessed 23 Mar 2021.

55. World Health Organization. 2020. Improving vaccination demand and addressing hesitancy. https:// www.who.int/teams/immunization-vaccines-andbiologicals/essential-programme-on-

immunization/demand/. Accessed 23 Mar 2021.

56. Migriño J Jr, Gayados B, Birol KRJ, et al. Factors affecting vaccine hesitancy among families with children 2 years old and younger in two urban communities in Manila, Philippines. Western Pac Surveill Response. 2020;11:1.

57. Larson HJ, Hartigan-Go K, de Figueiredo A. Vaccine confidence plummets in the Philippines following dengue vaccine scare: why it matters to pandemic preparedness. Hum Vaccin Immunother. 2019;15: 625-7.

58. World Health Organization Model List of Essential Medicines, 21st List, 2019. Geneva: World Health Organization; 2019. Licence: CC BY-NC-SA 3.0 IGO.

59. von Mollendorf C, Dunne EM, La Vincente S, et al. Pneumococcal carriage in children in Ulaanbaatar, Mongolia before and one year after the introduction of the 13-valent pneumococcal conjugate vaccine. Vaccine. 2019;37:4068-75.
60. Turner P, Turner C, Suy K, et al. Pneumococcal infection among children before introduction of 13 -valent pneumococcal conjugate vaccine, Cambodia. Emerg Infect Dis. 2015;21:2080-3.

61. Su WJ, Lo HY, Chang CH, et al. Effectiveness of pneumococcal conjugate vaccines of different valences against invasive pneumococcal disease among children in Taiwan: a nationwide study. Pediatr Infect Dis J. 2016;35:e124-33.

62. Suy K, Suon K, Ly S, et al. Pneumococcal colonisation in Cambodian children one year post-PCV13 introduction. Presented at: International Symposium on Pneumococci \& Pneumococcal Diseases, June 26-30, 2016; Glasgow, Scotland.

63. Lu CY, Chiang CS, Chiu CH, et al. Successful control of Streptococcus pneumoniae 19A replacement with a catch-up primary vaccination program in Taiwan. Clin Infect Dis. 2019;69:1581-7.

64. Chen $\mathrm{CH}, \mathrm{Su} \mathrm{LH}, \mathrm{Li} \mathrm{HC}$, et al. Evaluation of the impact of 13-valent pneumococcal conjugate vaccine immunization in children by surveillance of culture-confirmed pneumococcal disease: a prospective clinical microbiological study. Vaccine. 2019;37:5147-52.

65. Turner P, Leab P, Ly S, et al. Impact of 13-valent pneumococcal conjugate vaccine on colonization and invasive disease in Cambodian children. Clin Infect Dis. 2020;70:1580-8.

66. Riaz A, Mohiuddin S, Husain S, et al. Effectiveness of 10-valent pneumococcal conjugate vaccine against vaccine-type invasive pneumococcal disease in Pakistan. Int J Infect Dis. 2019;80:28-33.

67. Jaiswal N, Singh M, Das RR, et al. Distribution of serotypes, vaccine coverage, and antimicrobial susceptibility pattern of Streptococcus pneumoniae in children living in SAARC countries: a systematic review. PLoS One. 2014;9:e108617.

68. Takeuchi N, Naito S, Ohkusu M, et al. Epidemiology of hospitalised paediatric community-acquired pneumonia and bacterial pneumonia following the introduction of 13-valent pneumococcal conjugate vaccine in the national immunisation programme in Japan. Epidemiol Infect. 2020;148:e91.

69. Rhodes J, Dejsirilert S, Maloney SA, et al. Pneumococcal bacteremia requiring hospitalization in rural Thailand: an update on incidence, clinical characteristics, serotype distribution, and antimicrobial susceptibility, 2005-2010. PLoS One. 2013;8: e66038.

70. Phongsamart W, Srifeungfung S, Chatsuwan T, et al. Changing trends in serotype distribution and antimicrobial susceptibility of Streptococcus 
pneumoniae causing invasive diseases in Central Thailand, 2009-2012. Hum Vaccin Immunother. 2014;10:1866-73.

71. Nakano S, Fujisawa T, Ito Y, et al. Serotypes, antimicrobial susceptibility, and molecular epidemiology of invasive and non-invasive Streptococcus pneumoniae isolates in paediatric patients after the introduction of 13-valent conjugate vaccine in a nationwide surveillance study conducted in Japan in 2012-2014. Vaccine. 2016;34:67-76. 